\title{
Genomics of Preterm Birth
}

\author{
Kayleigh A. Swaggart ${ }^{1}$, Mihaela Pavlicev ${ }^{1,2}$, and Louis J. Muglia ${ }^{1,2}$ \\ ${ }^{1}$ Center for Prevention of Preterm Birth, Perinatal Institute, Cincinnati Children's Hospital Medical Center, \\ Cincinnati, Ohio 45229 \\ ${ }^{2}$ Department of Pediatrics, University of Cincinnati College of Medicine, Cincinnati, Ohio 45229 \\ Correspondence: louis.muglia@cchmc.org
}

The molecular mechanisms controlling human birth timing at term, or resulting in preterm birth, have been the focus of considerable investigation, but limited insights have been gained over the past 50 years. In part, these processes have remained elusive because of divergence in reproductive strategies and physiology shown by model organisms, making extrapolation to humans uncertain. Here, we summarize the evolution of progesterone signaling and variation in pregnancy maintenance and termination. We use this comparative physiology to support the hypothesis that selective pressure on genomic loci involved in the timing of parturition have shaped human birth timing, and that these loci can be identified with comparative genomic strategies. Previous limitations imposed by divergence of mechanisms provide an important new opportunity to elucidate fundamental pathways of parturition control through increasing availability of sequenced genomes and associated reproductive physiology characteristics across diverse organisms.

Preter reterm birth, defined as birth at $<37$ wk of gestation, is the leading cause of infant mortality around the world and a critical area for investigation leading to new preventative strategies (March of Dimes et al. 2012). In the United States, $\sim 11.5 \%$ of pregnancies end preterm, affecting 450,000 newborns (Hamilton et al. 2013). Despite the magnitude, impact, and costs of prematurity, relatively few advances have been made in prevention, particularly for early preterm births at $<34$ wk of gestation. Over the last $8 \mathrm{yr}$, rates of preterm birth have declined from $12.8 \%$ in 2006 to its current level, largely because of heightened measures to avert elective delivery before $39 \mathrm{wk}$ of gestation, limiting the potential for multiple gestation pregnancies from assisted reproductive technologies, and providing progesterone $(\mathrm{P} 4)$ supplementation to women at high risk for preterm birth related to having a previous preterm infant or a short cervical length (Muglia and Katz 2010).

Preterm birth is a broad outcome measure resulting from heterogeneous influences. These include infection (estimated at $25 \%$ of preterm birth), multiple gestations ( $\sim 3 \%$ of all pregnancies and $15 \%-20 \%$ of preterm births), and delivery for medical indications related to maternal or fetal complications such as preeclampsia or growth restriction $(\sim 30 \%$ of preterm births) (Goldenberg et al. 2008). The largest single category of preterm birth, however, remains spontaneous idiopathic, comprising

Editors: Diana W. Bianchi and Errol R. Norwitz

Additional Perspectives on Molecular Approaches to Reproductive and Newborn Medicine

available at www.perspectivesinmedicine.org

Copyright (C) 2015 Cold Spring Harbor Laboratory Press; all rights reserved; doi: 10.1101/cshperspect.a023127

Cite this article as Cold Spring Harb Perspect Med 2015;5:a023127 
K.A. Swaggart et al.

more than half of all of the preterm births in the spontaneous category. The inability to predict impending spontaneous idiopathic preterm birth, or intervene to prevent it, arises largely from the limited understanding of the causal mechanistic pathways, which could reflect early activation of normal parturition mechanisms or separate pathological exposures that disrupt usual timing mechanisms. Although experiments in model organisms have led to new insights for many human disorders, the advances for understanding the physiology of normal parturition and preterm labor and delivery have been relatively limited (Ratajczak et al. 2010). As will be discussed in this review, the divergence in regulation of endocrine signals heralding the onset of labor between mammals, likely to optimize individual species' reproductive success, has made extrapolation of findings in genetically altered mice, sheep, and even nonhuman primates, to human pregnancy unrevealing.

One relatively new, and potentially informative approach for elucidation of mechanisms of parturition and its timing, and thus the genetic loci potentially harboring variants increasing the risk for preterm birth, is through human genomics, encompassing both classical human genetics and more recent advances in understanding genome organization and function as a whole. Substantial evidence has accumulated that genetic factors, largely residing in the maternal genome, contribute up to $40 \%$ of the variation in birth timing and preterm birth. This evidence includes epidemiological data, analysis of birth timing to twins, and segregation analysis of pedigrees (Clausson et al. 2000; Kistka et al. 2008; Boyd et al. 2009; Plunkett et al. 2009). Moreover, with sequenced genomes now available for at least two dozen mammals at high coverage, and another dozen or more at lower coverage, the opportunity exists to use comparative genomic strategies to reveal genes and pathways that have been shaped through evolution to result in the current patterns of human and other mammal reproductive strategies and mechanisms.

In this review, we will first discuss the comparative physiology of different species related to the maintenance and termination of preg- nancy. We will then describe comparative genomic approaches that may reveal insights into convergent and divergent trait selection and critical targets for initiation of labor at term or preterm. Finally, we will describe current genome-wide, nonbiased approaches that are being used to reveal risk loci for preterm birth.

\section{ANIMAL MODELS: UNDERSTANDING MECHANISMS THROUGH COMPARISON}

To understand, prevent, and treat preterm birth, we should first understand the mechanisms behind normal birth timing. One approach is to examine the evolutionary history of the phenotypic traits relevant to human pregnancy and birth. Experimental work in model animals, predominantly sheep, mice, and livestock, has been a rich source of information on female reproductive characteristics, ranging from implantation to parturition and preterm birth. However, the relevance of this information for understanding the defects of human pregnancy and parturition is repeatedly questioned (Mitchell and Taggart 2009). Indeed, many reproductive features have undergone substantial evolutionary divergence across mammalian species, as exemplified by the diversity of the relative gestation lengths, litter sizes, or the roles of maternal and fetal signals in initiating parturition. Complicating the apparent divergence between species, some of the phenotypic similarities of model animals have been found to be superficial, arising from secondary convergence of ancestrally different processes, such as is the case for P4 withdrawal and placental P4 production in sheep and guinea pig (explained below). A criterion for the use of model animals in human research is that the processes modeled are homologous with those in humans; however, no established animal model appears to represent a full set of human reproductive features.

To be able to use model animals directly to infer human conditions, it is therefore critical to understand which mechanisms are conserved and how others are changed. It is reasonable to assume that most evolutionary change occurs by modification of existing features rather than by their replacement, so even divergent traits 
will maintain some degree of common developmental-genetic basis. Thus, in spite of inadequacy of every single model to fully represent human pregnancy, much insight can be gained by comparison across animal models. Here, we will briefly outline this point by examining the evolution of $\mathrm{P} 4$ functions across species.

\section{Evolution of Progesterone Functions}

The mammalian pregnancy-maintaining function of $\mathrm{P} 4$ refers to the suite of actions that are overcome or interrupted at parturition. These functions in humans include preparation of endometrium for implantation, suppression of the immune system, and maintenance of myometrial quiescence. The early embryo-supportive activity of $\mathrm{P} 4$ was already present in oviparous ancestors that humans share with extant reptiles and birds, thus predating pregnancy. In extant representatives of oviparous reptiles and birds, P4 enhances glandular secretions as the egg passes through the reproductive tract. In the subsequent transition to live-bearing (vivipary), as the production of the eggshell is reduced or abolished and the embryo is retained in the female reproductive tract, $\mathrm{P} 4$ gains stronger nourishing function. Fully evolved mammalian pregnancy is characterized by an extended period of high $\mathrm{P} 4$ production relative to the nonpregnant ovarian cycle, leading to the birth of live offspring. In some of the basal marsupials however, such as grey short-tailed opossum Monodelphis domestica, live birth occurs without prolongation of the maternal ovarian cycle (Fadem and Rayve 1985; Freyer et al. 2003; Wagner et al. 2014), and thus does not coincide with maternal "recognition" of pregnancy. The fact that in utero development and birth take place in these species without manipulation of maternal $\mathrm{P} 4$ production, and are furthermore shorter than the usual ovarian cycle (i.e., parturition occurs at high levels of P4), suggests that alternative mechanisms are in place that cause birth that are ancestral to systemic $\mathrm{P} 4$ withdrawal. The main pathway of marsupial birth involves prostaglandins (PGs) associated with inflammatory processes, which may therefore represent an ancestral mechanism of mammalian birth (Ren- free et al. 1994). In birds and oviparous reptiles, PGs from the ovary are involved in ovulation and in moving the egg through the oviduct by pulsation (Guillette 1990; Guillette et al. 1991), suggesting the ancestral function. Differences in involvement of PGs between oviposition and parturition have been reported (Gobbetti et al. 1993); however, vivipary evolved multiple times independently in reptiles and hence it is not clear to what extent these PG functions have been derived in parallel.

In mammals, $\mathrm{P} 4$ during the ovarian cycle is produced in the ovarian corpus luteum (CL), which is the remainder of a burst egg follicle. In the absence of a conceptus, $\mathrm{P} 4$ production by the CL diminishes. The prolongation of intrauterine development is achieved by the maintenance of CL P4 production in the presence of a conceptus. This prolongation is associated with implantation of the conceptus in the uterine wall and coincides in evolution with P4 acquiring an additional function, namely to suppress maternal inflammatory reactions, including the PG pathway ancestrally involved in birth. Evolution of this interaction between P4 and PG appears necessary for implantation and prolonged pregnancy. Interestingly, however, the opposite interaction also evolved: PGs cause perishing of the CL (luteolysis) and thus negatively impact $\mathrm{P} 4$ levels. Whether this interaction is ancestral or may have become necessary to antagonize P4's newly acquired anti-inflammatory function is not clear. At least in extant species, PGs have been shown to overcome the suppressive function of $\mathrm{P} 4$ leading to birth at high P4 levels (see below). The evolution of prolonged pregnancy thus appears to have coincided with the coupling of proinflammatory birth mechanisms involving PGs with P4 dynamics (Fig. 1).

\section{Pregnancy Pre- and Postluteolysis}

Luteal P4 production is in some species supplemented, or in the later stages of pregnancy fully replaced, by placental $\mathrm{P} 4$ production (the socalled luteo-placental shift) (Csapo 1969). The proportion of gestational length that is covered by the luteal P4 production thus differs across 
K.A. Swaggart et al.

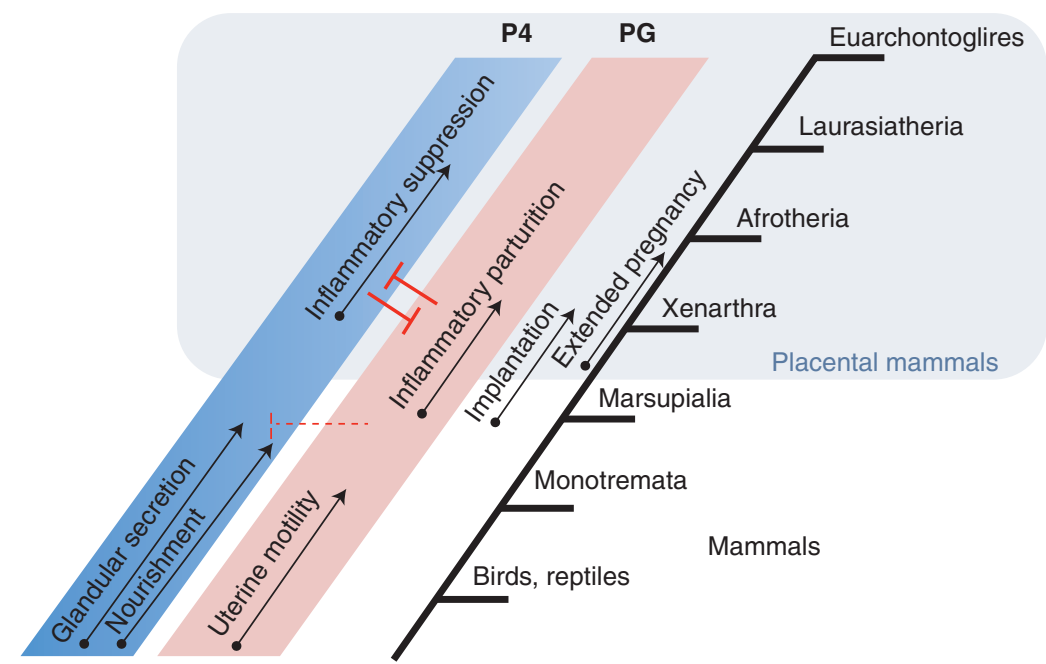

Figure 1. The evolving roles of progesterone (P4) and prostaglandins (PG) in reproduction. The extended pregnancy coincides with coupling of prostaglandins with progesterone dynamics.

taxa. Interestingly, when compared with the degree of embryo development, it seems that luteal $\mathrm{P} 4$ production corresponds well with the period of general organogenesis, and what varies is rather the length of intrauterine development that exceeds this developmental stage. For example, in mice, $\mathrm{P} 4$ is produced in the CL for the whole length of gestation, and progeny are born at an early developmental stage. In the long human gestation, organogenesis similarly occurs very early with most of the organogenesis accomplished by the time of luteolysis and the luteo-placental shift at 8 to 12 wk of gestation. This period is followed by a long growth period during which $\mathrm{P} 4$ is produced in the placenta. The luteo-placental shift is also a characteristic of sheep and occurs at $\sim 60 \mathrm{~d}$ of gestation. Similar to humans, the luteal period preceding the shift to placental production also roughly coincides with organogenesis. Similarly, guinea pig, a rodent with luteo-placental shift at $30 \mathrm{~d}$ of gestation (Csapo et al. 1981a,b), is born at $\sim 68 \mathrm{~d}$ at an advanced developmental stage. It is tempting to conclude that the second and third trimesters of human, sheep, and guinea pig gestation have no homologous period in mouse or other species in which gestation is completed within the luteal period. This observation may have interesting consequences for understand- ing the evolution of intrauterine development, pregnancy control and parturition.

Whereas the above developmental pattern appears stable in boreotheria (the lineage derived from the common ancestor of cow and humans) (Fig. 2), the mode of prolonged P4 production in basal eutherian lineages of Afrotheria and Xenarthra (such as hyrax, elephant or armadillo) appears more variable, as far as details are known. For example, the very long intrauterine development in African elephants (22 mo gestation) is supported in its full length by the luteal P4. The intrauterine development, at least as measured by the skeletal development, shows a prolonged pattern similar to species with a luteo-placental shift. The degree of ossification comparable to mice at birth is reached at one-third of gestation length (Hautier et al. 2012). This suggests that African elephants developed an alternative solution to a luteo-placental shift by prolonging $\mathrm{P} 4$ production in the CL. Indeed it has been shown that, despite being mono-ovulatory, elephants produce accessory CLs that luteinize without ovulation and maintain P4 levels throughout gestation (Lueders et al. 2012; Stansfield and Allen 2012). This is particularly interesting as the accessory corpora lutea have been found in several other species, such as horse and several mon- 
Genomics of Preterm Birth

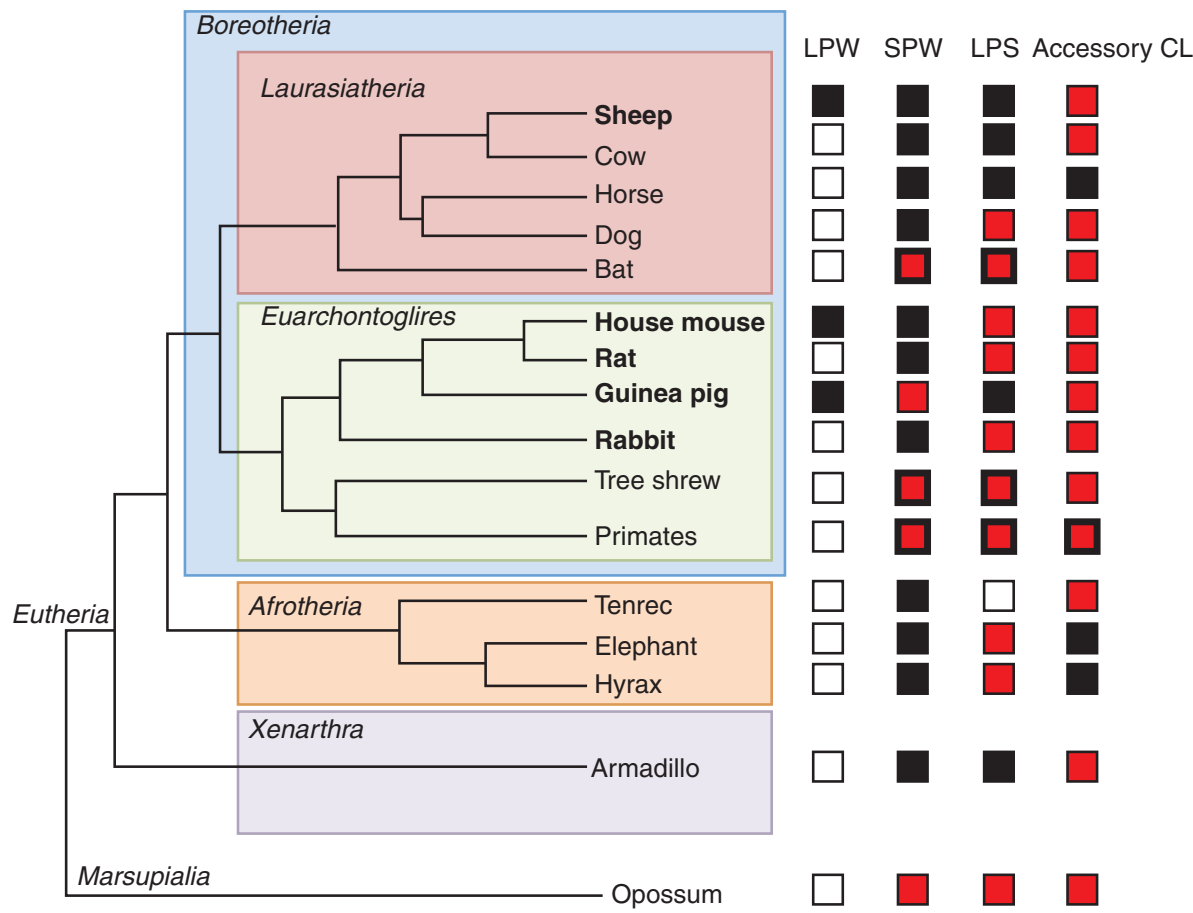

Figure 2. Phylogenetic tree of placental mammals (eutherians), with marsupials as outgroup. Model species are shown in bold. Local progesterone withdrawal (LPW) refers to the evidence for progesterone withdrawal in a particular tissue, such as cervix in mice or placenta in sheep, regardless of the presence of systemic progesterone decrease (SPW). Black indicates presence, red absence of a phenomenon, and white is the lack of information. Bicolored boxes indicate heterogeneity across species of a group. LPS, luteo-placental shift (i.e., the dependence on ovarian P4 is shorter than gestational time); CL, corpus luteum. Note the lack of information on local progesterone withdrawal.

keys; however, in these species, the P4 production in later stages of gestation is primarily placental. Representative of another lineage that separated early on from the lineage leading to primates, the nine-banded armadillo shows a yet different strategy. In this species, the $\mathrm{P} 4$ decrease postimplantation suggests luteolysis, followed by the main $\mathrm{P} 4$ production in the fetal adrenal gland and possibly also the placenta (Labhsetwar and Enders 1968; Nakakura et al. 1982). More detailed examination of these basal lineages will be interesting in the future.

\section{What Can Animals Reveal About Human Pregnancy and Parturition Despite Their Divergence?}

Even if late gestation is indeed not homologous across all mammals, P4 function in pregnancy maintenance may be sufficiently similar that its interruption, that is, parturition, is not fundamentally different. As mentioned above, parturition is in most animals an inflammatory event. The $\mathrm{P} 4$ functions involved in maintaining pregnancy in all mammals consist of immunosuppression and the maintenance of myometrial quiescence, in which the latter function may be either a consequence of the former or a separate function (Mendelson 2009).

Systemic levels of P4 do not drop before parturition in humans and higher primates, implying that either an alternative mechanism induces inflammation or the effect of $\mathrm{P} 4$ is modified downstream from its production. However, these characteristics may not be distinctive of higher primates. Mechanisms of local modification of P4 levels have been shown in mouse (Word et al. 2005; Mendelson 2009). 
K.A. Swaggart et al.

Despite systemic P4 withdrawal, P4 levels in mouse at birth are still well exceeding $\mathrm{Kd}$ for binding to $\mathrm{P} 4$ receptor $(\mathrm{PR})$ and the $\mathrm{P} 4-\mathrm{su}-$ pressed processes require additional local P4 withdrawal. For example, withdrawal of P4 in cervix, leading to cervix ripening, requires local P4-catabolic enzyme 5 $\alpha$-reductase type I (Mahendroo et al. 1999). Thus, also in mice, and supposedly in other species with systemic P4 decrease, the actual effects of P4 withdrawal on inflammatory and procontractile pathways require local mechanisms.

The proposed mechanisms of functional P4 withdrawal in human parturition will be addressed in later sections. Here, we briefly consider how the pregnancy-maintaining functions of P4 are modified or bypassed in animal models that give birth at high P4 levels. Apart from the higher primates, high levels of $\mathrm{P} 4$ at birth are present in two genetically manipulated mouse models, as well as in guinea pig.

A mouse model that gives birth at high P4 levels resulted from generation of a hypomorphic allele of hydroxyprostaglandin dehydrogenase 15-(NAD) (Hpgd), the gene encoding the primary PG-catabolizing enzyme (Roizen et al. 2008). HPGD decreases toward the end of pregnancy, causing the increase of two PGs, the luteolytic PGF2 $\alpha$ and luteotropic PGE2. The investigators found that mice hypomorphic for Hpgd gave birth prematurely and did not undergo luteolysis, giving birth at high levels of $\mathrm{P} 4$. Thus, the effect of high systemic P4 on myometrial quiescence was overcome, decoupling luteolysis (i.e., P4 withdrawal) from PG action. The second mouse model, a uterine-specific deletion of Trp53, is similar in that it involves triggering preterm myometrial contractions via the PG pathway despite functional CL and correspondingly high $\mathrm{P} 4$ levels. In this case, increased PGF $2 \alpha$ was a consequence of increased levels of COX2, an enzyme necessary for PG synthesis (Cha et al. 2013). In both cases, the balance between the proinflammatory signals of PGs and anti-inflammatory signals of P4 shifted locally in the myometrium, independently of the fetal developmental stage, toward proinflammation and hence birth, by causing a premature increase in PG.
The third model is the guinea pig, a representative of a lineage with a luteo-placental shift similar to humans, maintaining high systemic P4 levels throughout gestation. The detailed mechanisms of birth in guinea pig are not well understood. However, recent work on cervix found expression of P4-metabolizing enzymes in term cervix, suggesting that the shift toward proinflammatory activity of birth is triggered by potentially independently evolved local P4 withdrawal (Nnamani et al. 2013). Notably, local withdrawal also appears to be the main mechanism in sheep, which, like primates, experience the luteal-placental shift, but also show overt P4 withdrawal at term. Reduction of P4 in this species near term is achieved by enzymatic conversion to estrogen via sheepspecific enzyme P450c17. This conversion is stimulated by fetal cortisol secretion (Liggins et al. 1973; Anderson et al. 1975; Challis et al. 2000, 2005). Although human fetal cortisol also increases toward term, P4 levels do not decrease by this mechanism. The multiple mechanisms of functional P4 withdrawal, albeit developed to target different levels of systemic P4, may be a general characteristic in mammals rather than an alternative to systemic withdrawal. Extending the limited knowledge in various species of these mechanisms, occurring regardless of the decrease of systemic P4, is a promising future avenue. As suggested by Nnamani et al. (2013) for the guinea pig, preliminary insights can be attained via transcriptomic analyses.

\section{What May Drive Different Levels of Progesterone Across Species?}

P4 likely acquired further functions in development, and only the pregnancy maintaining (anti-inflammatory) function needs to be overcome to trigger birth. The required systemic levels of P4 may be determined by the functions of $\mathrm{P} 4$ other than its anti-inflammatory role. Differences between species might therefore be found in what other functions P4 fulfills and how locally the anti-inflammatory function must be overcome. These additional functions of P4 appear to have evolved after the prolon- 
gation of pregnancy to include postluteal intrauterine development.

The mechanism proposed to mediate the evolution of pregnancy and parturition, and in particular of P4 signaling, is the maternalfetal resource conflict, in which fetus prolongs and intensifies the pregnancy at the cost of the mother, and mother develops alternative mechanisms to stop the pregnancy. Evolution of fetal P4 production and its escape from maternal luteolysis can be interpreted this way. An alternative hypothesis could be that some of the newly evolved roles of $\mathrm{P} 4$, such as those in embryonic development or in maternal metabolism, preclude systemic P4 withdrawal before birth. P4 has been shown to play a role in lung development (Beyer et al. 2003; Trotter et al. 2006, 2009) as well as in neurological development (Wagner 2008; Yawno et al. 2014). These two organs manifest prolonged development in humans (and in guinea pig; Sosenko and Frank 1987), as evidenced by a majority of the defects from preterm birth being of neurological and pulmonary nature. It is tempting to speculate that the evolution of a metabolically costly brain (Clancy et al. 2007), in particular given its growth spurt immediately following birth, may require lungs with exceptional capacity and long development. Moreover, high P4 levels may benefit the maternal side, increasing maternal respiratory efficiency (Irwin et al. 2008), given particularly high metabolic demands in precocial primates (Dunsworth et al. 2012). The evolution of P4's role may therefore involve striking a balance between its different functions, only some of which must be overcome for birth to occur. A comparative study of manifold P4 functions across model species may be the best approach to understand the roles of P4 in humans. Knowledge of the contexts in which various functions were gained, lost or uniquely modified will help prioritize the relevant models in which to address specific defects of human pregnancy. Thus, rather than to reduce the research on pregnancy-related outcomes on model animals with the argument that animals are too distant to be relevant for human defects, it may be the inclusion of a wide range of vertebrates in phylogenetically in- formed comparative studies that will be crucial for understanding the underlying mechanistic basis of human traits.

\section{EVOLUTIONARY GENOMICS OF PROGESTERONE SIGNALING}

Evolution is a genomic event, with natural selection acting on diversity in form and function that is created by variation in the genome. Understanding of the evolutionary history of a gene or system of interest can be powerful for determining not only why the current mechanisms exist as they do, but also how they function and how they might be manipulated to anticipate and prevent negative outcomes. Despite the essential role reproduction plays in the life cycle and the significant impact of preterm birth, the biological processes behind human parturition are only partially understood. As shown above, despite their potential limitations, model organisms can be a valuable resource and P4 signaling in pregnancy maintenance and the initiation of parturition provides an excellent example. Understanding the molecular evolutionary history of the effects of steroid hormones on birth has shed significant light on key aspects of the biological mechanisms involved and can help point to potential targets for the study, prevention and treatment of preterm birth.

\section{Evolution of the Progesterone Receptor}

The scope of $\mathrm{P} 4$ function is wide and its specific role in ovulation, the menstrual cycle and the establishment and maintenance of pregnancy is well established. However, much less is known about its function in signaling human parturition because humans and other primates differ significantly from other species in that they do not experience overt P4 withdrawal before labor (Ratajczak et al. 2010). P4 signaling is mediated through the nuclear $\mathrm{P} 4$ receptor (PR) and much attention has been focused on understanding its evolutionary history and function. Identification of a P4-responsive receptor in an extant invertebrate suggests that P4's role in reproductive traits is ancient (Stout et al. 2010). In ver- 
K.A. Swaggart et al.

tebrates, PR is one of six steroid receptors, along with estrogen receptors $\mathrm{ER} \alpha$ and $\mathrm{ER} \beta$, androgen receptor (AR), glucocorticoid receptor (GR) and mineralocorticoid receptor (MR) (Thornton 2001). Sequence data suggest that all extant steroid receptors are descendants of a single ancestral receptor that was sensitive specifically to estrogen and present by $0.6-1.2$ billion years ago (Thornton 2001; Thornton et al. 2003). The additional receptors present in vertebrates today are the result of multiple large-scale duplication events, a common mechanism for creating diversity in function despite selective pressure to keep the ancestral mechanism intact, such as estrogen-mediated signaling. P4 and other hormones like testosterone are intermediate products in the synthesis of estrogen. Therefore, these molecules would have existed before duplicated estrogen receptors evolved to recognize and respond to them. Examination of the ligand binding domain sequences of the reconstructed ancestral steroid receptors suggests that just two nonsynonymous changes dramatically shifted ligand affinity from estrogen to the androgens, progestens, glucocorticoids and mineralocorticoids (Harms et al. 2013). This finding illustrates the utility of examining the molecular evolutionary history of genes and proteins of interest to better understand their current functions and to identify crucial bases or motifs that may influence protein function or preterm birth risk if variable.

\section{Mechanisms of Progesterone Withdrawal}

Evolutionary thought suggests that the development of functional P4 withdrawal is a gestationshortening maternal response to gestationlengthening fetal control of P4 production via the placenta (Haig 1993; Wagner et al. 2012). The potential mechanisms behind functional P4 withdrawal in humans have been extensively examined, and will be reviewed in the following section.

$\mathrm{P} 4$ receptors act as transcriptional regulators on ligand binding. Of particular interest are two of the $\mathrm{P} 4$ receptor's isoforms, PR-A and $\mathrm{PR}-\mathrm{B}$, which are the products of distinct promoters and transcription start sites (Kastner et al. 1990). PR-A lacks an amino-terminal region, containing a transcription activation function domain, which is present only in PRB (Sartorius et al. 1994). PR-B functions largely as a transcriptional activator for genes involved in maintaining pregnancy, whereas PR-A leads to the repression of PR-B activity (Vegeto et al. 1993). Through most of pregnancy, PR-B expression makes up a majority of the total PR present in the myometrium, but as pregnancy progresses toward term, PR-A expression is increased (Mesiano et al. 2002; Mesiano 2004; Merlino et al. 2007). This observation, along with the repressive effect of PR-A on PR-B function, has provided considerable support for the "isoform switch hypothesis" (ISH) for functional P4 withdrawal. This hypothesis proposes that an increase in the relative abundance of PR-A versus PR-B leads to the repression of $\mathrm{PR}-\mathrm{B}$ and a reduction in the transcription of pregnancy-promoting genes, effectively priming the uterus for parturition despite increasingly high levels of propregnancy P4. This increase in the relative abundance of PR-A versus PR-B toward term, however, is not isolated to species that lack systemic P4 withdrawal.

Mice experience overt P4 withdrawal but also an increase in the PR-A/PR-B ratio as term approaches (Zeng et al. 2008), suggesting that PR isoform switching may be ancestral to functional P4 withdrawal (Wagner et al. 2012). There is also some evidence that human PR-B may actually be less sensitive to the repressive effect of PR-A than would be expected if the isoform switch hypothesis fully explains functional P4 withdrawal. In an in vitro assay, human PR-B was shown to be less sensitive to PRA than mouse, the opposite of what would be expected if the isoform switch hypothesis were correct. However, the study did not examine the responsiveness of human PR-B in an expression ratio with PR-A consistent with that seen in the myometria of women at term and in labor, so threshold requirements for significant PR-B repression cannot be ruled out.

In support of a unique role of the $\mathrm{P} 4$ receptor and isoform switching in human parturition is evidence of positive selection in the gene specifically in humans and chimpanzees 
(Chen et al. 2008). Evidence for historical selection events can be determined by examining the sequence of a gene of interest and evaluating the impact of variation observed across many species. Positive selection is marked by more amino acid changing variants than variants that do not affect the protein sequence. An abundance of protein, and potentially function, changing polymorphisms indicates that, at one point in time, change was largely tolerated, likely in an effort to diversify function. Purifying selection, on the other hand, is marked by more synonymous variation, suggesting a necessarily conserved protein sequence and function not tolerant to change. Neutral selection is represented by an equal distribution of synonymous and nonsynonymous polymorphisms. Humans show the highest level of positive selection signature in the PR gene and most changes versus other species occur in the $5^{\prime}$ region of the gene. Specifically, changes occur in the inhibitory function (IF) domain, which is responsible for the transrepression of $\mathrm{PR}$, and the $\mathrm{PR}-\mathrm{B}$-specific activating function domain (Chen et al. 2008). All but one of these variants became fixed in the human lineage, suggesting that whatever new characteristics these polymorphisms created were subsequently selected for and tightly conserved. The location of these variants in humans and chimpanzees versus other species indicates that they could play an important and unique role in the regulation of PR-B by PR-A.

\section{Genetic Variation and Progesterone Receptor Function}

Genetic factors are known to play a significant role in the risk for preterm birth and an obvious starting point in the search for genetic variation influencing P4 function, and therefore parturition, is in the $\mathrm{P} 4$ receptor itself. Initially described in studies of ovarian cancer risk, a common variant in human PR is PROGINS (Rowe et al. 1995; Agoulnik et al. 2004). The PROGINS allele is present at a frequency of $>20 \%$ in some populations (Donaldson 2002) and is a group of three variants in complete linkage disequilibrium: one synonymous variant; one nonsynonymous variant (V660L); and an intronic human-specific Alu retrotransposon insertion (Romano et al. 2007). The PROGINS PR has been shown to be less sensitive to the effects of P4 (Romano et al. 2007). It is conceivable that the PROGINS allele affects pregnancy and parturition either directly through $\mathrm{P} 4$ responsiveness or indirectly through increased risk for conditions associated with preterm birth. A possible connection is not clear, as studies examining recurrent miscarriage and preterm birth did not find significant association with PROGINS genotype (Kurz et al. 2001; Diaz-Cueto et al. 2008). However, in a study testing for maternal and fetal effects of PR gene variation on preterm birth risk, suggestive maternal associations were identified for SNPs ( single-nucleotide polymorphisms) in complete LD with PROGINS. Suggestive fetal associations with SNPs upstream of $\mathrm{PR}$ and not in LD with PROGINS were found and hint at the possibility of regulatory variation and alternate maternal and fetal mechanisms in PR mediated preterm birth risk (Ehn et al. 2007) (for related studies in PR polymorphisms, see also Guoyang et al. 2008; Manuck et al. 2010a,b, 2011).

Examination of the role of $\mathrm{P} 4$ in parturition across species and comparative genomics have led to important insights about both the history of hormone signaling in labor and human-specific adaptations and mechanisms. Although questions remain about how parturition is initiated in humans, the importance of $\mathrm{P} 4$ is clear, as P4 antagonists are capable of triggering labor at any stage of gestation (Neilson 2000). Despite this, many other genes and pathways play a critical role in birth timing and are possible candidates for influencing preterm birth. Study of these systems in the context of evolutionary changes and selective pressures can also produce significant insights and several examples are discussed below.

\section{COMPARATIVE GENOMICS BEYOND PROGESTERONE}

\section{Fetal Membrane Rupture}

Although hormone signaling is a significant driver in the initiation of parturition, other fac- 
K.A. Swaggart et al.

tors play a key role as well. Rupture of the fetal membranes is particularly important and preterm premature rupture of membranes (PPROM) is a significant cause of preterm birth (Goldenberg et al. 2008). The evolutionary history of membrane rupture is diverse in mammals and has shed some light on genes and variants that may play a role in this mechanism. Although exceptions exist, the vast majority of human and primate newborns are delivered with completely ruptured fetal membranes. In contrast, some species deliver with a fully intact gestational sac. Evolutionary analysis of this trait revealed that the ancestral state is likely delivery with a fully ruptured sac, with partial or fully intact membranes at delivery evolving multiple times in mammals (Stempfle et al. 2013). Previous studies have implicated a number of genes involved in connective tissue disorders as also having a potential role in PPROM, particularly when the fetus is affected (Anum et al. 2009). Examination of these genes in the context of the evolutionary history of membrane rupture revealed evidence for adaptive evolution, or positive selection, particularly in lineages that evolved intact membranes at birth (Stempfle et al. 2013). These findings can point to potentially important functional sites in genes involved in fetal membrane structure-whether highly conserved in all species or altered in species with different rupture mechanisms.

\section{Repetitive Elements and the Invasive Placenta}

Repetitive elements make up a significant portion of the human genome (Deininger and Batzer 2002) and have been implicated time and again in the evolution of regulatory networks because they are known to contribute novel regulatory elements that can be recruited by the host genome (Feschotte 2008). Several examples with potential relevance to pregnancy and birth timing have been identified in humans. The evolution of decidual prolactin (dPRL) expression in humans, which is expressed from a promoter different from that used in the pituitary, was significantly influenced by the integration of two transposable elements: MER20, a
DNA transposon present in all placental mammals, and MER39, a long terminal repeat (LTR) found in primates and rodents (Emera and Wagner 2012). In vitro evaluation of the PRL MER20 element suggested an insulator role in humans, possibly maintaining open chromatin structure, and therefore availability to transcriptional regulators, in PRL and other genes with nearby MER20 elements (Lynch et al. 2011). MER39 is thought to have a significant impact on the expression of dPRL in humans as a result of a number of ape-specific nucleotide replacements creating consensus transcription factor binding sites in conjunction with sites present in the LTR on genome insertion (Emera and Wagner 2012). Functional testing of the APRL promoter region indicated that the MER20/MER39 region did not immediately function as a decidua-specific PRL promoter, but evolved promoter activity that was subsequently strengthened in apes (Emera and Wagner 2012). Interestingly, PRL expression in the endometrium appears to have evolved independently in mice and elephants. In both cases, unique transposable elements were recruited to form the responsible promoter (Emera et al. 2012). This unique case of convergent evolution of both tissue-specific gene expression and the mechanism of expression shows the important part repetitive elements have played in key mechanisms of pregnancy.

The timing of the strengthening of $\mathrm{dPRL}$ expression in humans and apes coincided with the evolution of significant invasiveness of the placenta in these species. It is hypothesized that given dPRL's role in regulating the proliferation of uterine natural killer cells, which in turn may regulate placental invasion, the recruitment of MER20/MER39 to increase dPRL expression may have been a maternal response to the increasingly invasive fetal placenta (Emera and Wagner 2012). Defects in placental invasion can lead to preeclampsia, a known risk factor for medically indicated preterm delivery (Trilla et al. 2014). It is possible that variation in dPRL expression influences risk for such disorders (Golander et al. 1985) and potentially idiopathic preterm birth through more subtle alterations in placental function. 
Selective Pressures and Adaptive Evolution in Human Pregnancy and Parturition

Hypotheses about the selective pressures shaping the evolution of human pregnancy can help explain why extant physiological mechanisms might exist. As briefly described above, opposing maternal and fetal adaptations can appear when the optimal fitness interests of each are not the same. This is the basis of the maternal-fetal conflict hypothesis (Haig 1993). Maternal interests are likely to lie in producing as many healthy progeny as possible, therefore limiting resources expended on any one offspring. In contrast, fetal interests are likely to be considerably more selfish and focus on maximizing maternal resources used to optimize maturation. This idea is the foundation of evolutionary hypotheses that attempt to explain features unique to human birth timing such as difficult physical delivery and the relatively immature nature of human neonates.

Human neonates are born with the most underdeveloped brain of all primates at just $30 \%$ of adult brain size (DeSilva and Lesnik 2006). This constriction of head size at birth is often explained by two evolutionary ideas: the obstetric dilemma (OD) and the energetics of gestation and growth (EGG) hypotheses. Both hypotheses agree that neonatal head size is constrained before birth. Because increased brain size is considered a selective advantage, opposing selective pressures must exist to limit growth in utero, which results in the birth of very developmentally immature neonates compared with other primates. Despite this, humans still experience difficult childbirth owing to cephalopelvic disproportion-large heads that must move through a narrow pelvis (Rosenberg and Trevathan 2002). Although not mutually exclusive, the hypotheses differ in what opposing selective pressures may have resulted in these changes in humans. The OD hypothesis posits that selection for the pelvic bone structure required for efficient bipedalism is the driver behind limiting fetal head size, allowing growth to continue only until it reaches the limits of the pelvis to accommodate the fetus during childbirth (Wittman and Wall 2007; Weiner et al. 2008).
In contrast, the EGG hypothesis argues that limits on maternal energy available to the growing fetus are more important in determining gestation length (Dunsworth et al. 2012). More specifically, mothers have a finite amount of energy they can expend on themselves and a growing fetus, which requires increasing amounts of energy for development as term nears. The EGG hypothesis suggests that gestation is triggered by metabolic stress when mothers reach their threshold of maximum energy expenditure. When this limit is reached, neonates are still capable of navigating the birth canal, albeit with difficulty. This hypothesis is supported by data demonstrating a consistent metabolic ceiling in humans that is approached toward the end of gestation (Hammond and Diamond 1997; Dunsworth et al. 2012).

Whether the timing of human gestation can be explained by constraints such as maternal pelvic dimensions, metabolic limits or other factors, significant selective pressures were essential in shaping the current mechanisms of human birth timing and many other humanspecific adaptations. Signatures of these events are apparent in the human genome (Bamshad and Wooding 2003; Voight et al. 2006; Pickrell et al. 2009). Given the significant differences between humans and other primates, as shown by the OD and EGG hypotheses, it is thought that genes involved in birth timing are likely among those that show signs of adaptive evolution in humans (Plunkett et al. 2011). In support of this, a study examining the signatures of selection in preterm birth candidate genes revealed a subset showing evidence of selection in humans. In addition, other genes and noncoding regions demonstrating accelerated evolution but not previously associated with preterm birth were identified (Fig. 3). One of these genes, follicle stimulating hormone receptor $(F S H R)$, showed association with preterm birth in case/control cohorts of mothers of Finnish and African-American ancestry. Variants in FSHR have been linked to female infertility (Lalioti 2011), a known risk factor for preterm birth. Suggested function in the uterus and cervix and an influence on PR isoform abundance in mice (Danilovich et al. 2002), provide further 
K.A. Swaggart et al.

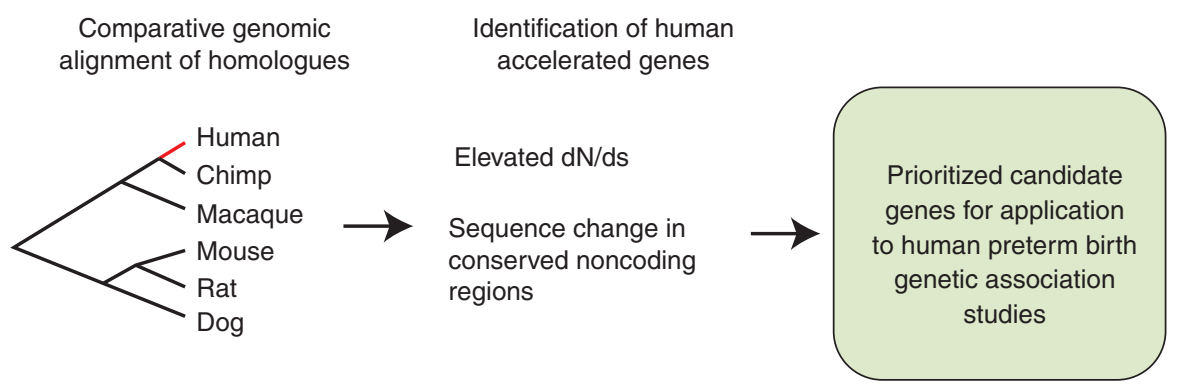

Figure 3. Strategy for using comparative genomics to identify human gene evolution associated with adaptations in birth timing and risk for preterm birth. Homologous genes are aligned, and coding region changes (increased number of nonsynonymous to synonymous nucleotide changes $(\mathrm{dN} / \mathrm{dS})$ or loss of constraint in conserved noncoding regions reveal human rate accelerated regions. Genes associated with these regions are then used as nonphysiologically biased candidates for association studies.

possibilities for its potential involvement in normal birth timing and preterm birth risk. Further examination revealed many common variants in FSHR and an association of noncoding SNP haplotypes with both preterm birth risk and protection (Plunkett et al. 2011; Chun et al. 2013). The putative causal variants in both haplotypes are predicted to alter binding site affinity for transcription factors with potential roles in the initiation of parturition (Chun et al. 2013). Although these findings were somewhat restricted to the examined Finnish cohort, they point to additional candidate genes and pathways for study in more broad populations. Another preterm birth candidate gene identified using the same population and unbiased accelerated evolution approach, cytosolic phospholipase A2 gamma (PLA2G4C), is involved in PG synthesis and was found to have a primate-specific insertion of a noncoding element (Plunkett et al. 2010). This element may have a general role in changes in PLA2G4C expression and PG's role in parturition observed between species with and without it, and common human SNPs in the gene associated significantly with preterm birth risk may further alter expression (Plunkett et al. 2010).

The identification and prioritization of candidate preterm birth risk alleles in noncoding regions, such as those in FSHR and PLA2G4C, can be significantly aided by the use of comparative genomics. Regions demonstrating accelerated evolution and positions with significant conservation or divergence are of particular interest. Many other genomic changes through evolution-such as gene duplications, copy number variants, or acquisition of new transposable elements modifying regulatory characteristics that map to specific pregnancy traitsalso hold enormous promise for new insights. By considering evolutionary history and comparative genomics, new hypotheses can be formed about the modern mechanisms of normal human birth timing. This will allow us to better understand and predict aberrations in these systems, most notably in preterm birth.

\section{GENOME-WIDE ANALYSES: FAMILIES, HUMAN POPULATIONS, AND SPECIES}

There have been several recent reviews summarizing the current state of knowledge for candidate gene association studies with human preterm birth in case-control cohorts or transmission disequilibrium designs (we refer readers to these sources for detailed descriptions: Crider et al. 2005; Committee on Understanding Premature Birth and Assuring Healthy Outcomes 2006; Plunkett and Muglia 2008; Bezold et al. 2013). In general, compelling evidence for specific genes as substantially contributing to or protecting from preterm birth risk has not emerged. Much of this work has focused on loci in inflammatory signaling cascades, coagulation factors pathways, and metabolizing enzymes. Because of limited progress with these 
targeted candidate methods, several groups embarked on nonbiased genome-wide studies.

Analysis of families with multiple members affected with a shared trait or disorder is a timeproven approach to the elucidation of single gene defects characteristic of simple Mendelian inheritance. Application to complex disorders, resulting from the influence of multiple loci, including preterm birth, has also met with success, although in a more limited scale. For example, Haataja et al. (2011) used linkage analysis to reveal that the IGF-1 receptor locus (IGF1R) in the fetal genome was associated with preterm birth in families from Finland. This finding was used to explore IGF1R as a candidate gene in the general population in which further supportive evidence was obtained (Haataja et al. 2011). The same group performed a specific analysis on these same families for possible $\mathrm{X}$ chromosome loci contribution to preterm birth risk. This approach resulted in identification of a linkage peak near the androgen receptor (AR) locus (Karjalainen et al. 2012). Families highly enriched for pregnancies ending in spontaneous preterm birth have also begun to be analyzed using whole exome sequencing to identify more highly penetrant rare variants contributing to preterm birth risk. The first study published using whole exome sequencing explored the concordance of shared variants in sister pairs having preterm children and revealed an over-representation of rare variants in the complement-coagulation factor pathway. This finding was reinforced with identification of rare variants in mothers from other densely affected families in these same genes (McElroyet al.2013). Results of findings in many more families with the whole exome or whole genome sequencing approaches are likely to emerge in the near future.

Several genome-wide association studies for preterm birth are currently underway or have been recently completed. To date, polymorphisms achieving genome-wide statistical significance for association with preterm birth risk have not been reported. In part, this may result from still a relatively low overall number of women and infants that have been genotyped (on the order of 8000 women, approximately equally divided between cases and controls, and a similar number of infants), and the variable geographical ancestry they represent. Importantly, several of these data sets have been deposited in Database of Genotypes and Phentoypes (dbGaP) (see http://www.ncbi.nlm.nih .gov/gap). Access to these data sources will allow a more sophisticated systems biology analysis to be undertaken beyond usual metaanalytic approaches analyzing only genotypes and adjustments for demographic factors (Uzun et al. 2012a,b, 2013). Integrating existing gene expression profiles of gestational tissues at various points during pregnancy, metabolomic signatures, and environmental exposure holds the promise of accelerating discovery even before acquisition of larger cohorts that will allow significance of small-effect size variants to emerge.

We previously discussed the emergence of viviparity and the divergence of reproductive strategies of placental mammals reflected by differences in litter size, fetus size, and maturity at the time of delivery, gestational length and hormone regulation in the context of evolution. One potentially useful "filter" for the analysis of human genome-wide data is the application of comparative genomic analysis across existing sequenced species to reveal loci that have undergone selection at the appropriate evolutionary junctions to potentially influence mechanisms of birth timing. Examples might include the timing for emergence of functional instead of systemic P4 withdrawal (this evolved independently along more than one lineage), or the changes in human-specific constraints to birth such as the expansion of human head size and the restricted size of the birth canal, in part as a consequence of bipedalism. This approach may significantly enhance our ability to detect variants contributing to preterm birth risk over current methods.

\section{CONCLUDING REMARKS}

In this review, we present an evolutionary framework for determining the molecular mechanisms for term parturition and preterm birth. Although human pregnancy and parturition experienced potential anatomical and energetic 
K.A. Swaggart et al.

constraints that were subject to selective pressures and required species-specific adaptations, a conserved toolbox of critical signaling molecules has been maintained. The most ancient amongst the tools in this toolbox are P4 and PGs, whose roles in reproduction preceded viviparity. Using comparative genomics to elucidate gene variation across different species, and their association with modifications in regulation of P4 and PG signaling, will both provide insights into normal trans-species reproductive processes as well as implicate new targets for focus in the genomes of women and infants experiencing preterm birth.

\section{ACKNOWLEDGMENTS}

L.J.M. and M.P. are supported by the March of Dimes Prematurity Research Center Ohio Collaborative.

\section{REFERENCES}

Agoulnik IU, Tong XW, Fischer DC, Korner K, Atkinson NE Edwards DP, Headon DR, Weigel NL, Kieback DG. 2004. A germline variation in the progesterone receptor gene increases transcriptional activity and may modify ovarian cancer risk. J Clin Endocrinol Metab 89: 6340-6347.

Anderson AB, Flint AP, Turnbull AC. 1975. Mechanism of action of glucocorticoids in induction of ovine parturition: Effect on placental steroid metabolism. J Endocrinol 66: $61-70$

Anum EA, Hill LD, Pandya A, Strauss JF III. 2009. Connective tissue and related disorders and preterm birth: Clues to genes contributing to prematurity. Placenta 30: 207215.

Bamshad M, Wooding SP. 2003. Signatures of natural selection in the human genome. Nat Rev Genet 4: 99-111.

Beyer C, Kuppers E, Karolczak M, Trotter A. 2003. Ontogenetic expression of estrogen and progesterone receptors in the mouse lung. Biol Neonate 84: 59-63.

Bezold KY, Karjalainen MK, Hallman M, Teramo K, Muglia LJ. 2013. The genomics of preterm birth: From animal models to human studies. Genome Med 5: 34 .

Boyd HA, Poulsen G, Wohlfahrt J, Murray JC, Feenstra B, Melbye M. 2009. Maternal contributions to preterm delivery. Am J Epidemiol 170: 1358-1364.

Cha J, Bartos A, Egashira M, Haraguchi H, Saito-Fujita T, Leishman E, Bradshaw H, Dey SK, Hirota Y. 2013. Combinatory approaches prevent preterm birth profoundly exacerbated by gene-environment interactions. J Clin Invest 123: 4063-4075.

Challis JRG, Matthews SG, Gibb W, Lye SJ. 2000. Endocrine and paracrine regulation of birth at term and preterm. Endocr Rev 21: 514-550.
Challis JR, Bloomfield FH, Bocking AD, Casciani V, Chisaka H, Connor K, Dong X, Gluckman P, Harding JE, Johnstone J, et al. 2005. Fetal signals and parturition. J Obstet Gynaecol Res 31: 492-499.

Chen C, Opazo JC, Erez O, Uddin M, Santolaya-Forgas J, Goodman M, Grossman LI, Romero R, Wildman DE. 2008. The human progesterone receptor shows evidence of adaptive evolution associated with its ability to act as a transcription factor. Mol Phylogenet Evol 47: 637-649.

Chun S, Plunkett J, Teramo K, Muglia LJ, Fay JC. 2013. Finemapping an association of FSHR with preterm birth in a Finnish population. PLOS ONE 8: e78032.

Clancy B, Finlay BL, Darlington RB, Anand KJ. 2007. Extrapolating brain development from experimental species to humans. Neurotoxicology 28: 931-937.

Clausson B, Lichtenstein P, Cnattingius S. 2000. Genetic influence on birthweight and gestational length determined by studies in offspring of twins. BJOG 107: $375-$ 381.

Committee on Understanding Premature Birth and Assuring Healthy Outcomes. Board on Health Sciences Policy. 2006. Preterm Birth: Causes, Consequences, and Prevention, The National Academies Press, Washington, D.C.

Crider KS, Whitehead N, Buus RM. 2005. Genetic variation associated with preterm birth: A HuGE review. Genet Med 7: 593-604.

Csapo A. 1969. The luteo-placental shift, the guardian of pre-natal life. Postgrad Med J 45: 57-64.

Csapo AI, Eskola J, Tarro S. 1981a. Gestational changes in the progesterone and prostaglandin $F$ levels of the guineapig. Prostaglandins 21: 53-64.

Csapo AI, Puri CP, Tarro S. 1981b. Relationship between timing of ovariectomy and maintenance of pregnancy in the guinea-pig. Prostaglandins 22: 131-140.

Danilovich N, Roy I, Sairam MR. 2002. Emergence of uterine pathology during accelerated biological aging in FSH receptor-haploinsufficient mice. Endocrinology 143: 3618-3627.

Deininger PL, Batzer MA. 2002. Mammalian retroelements. Genome Res 12: 1455-1465.

DeSilva J, Lesnik J. 2006. Chimpanzee neonatal brain size: Implications for brain growth in Homo erectus. J Hum Evol 51: 207-212.

Diaz-Cueto L, Dominguez-Lopez P, Cantillo-Cabarcas J, Perez-Figueroa G, Arechavaleta-Velasco M, Arechavaleta-Velasco F. 2008. Progesterone receptor gene polymorphisms are not associated with preterm birth in a Hispanic population. Int J Gynaecol Obstet 103: 153-157.

Donaldson CJ. 2002. PROGINS Alu insertion and human genomic diversity. Mutat Res 501: 137-141.

Dunsworth HM, Warrener AG, Deacon T, Ellison PT, Pontzer H. 2012. Metabolic hypothesis for human altriciality. Proc Natl Acad Sci 109: 15212-15216.

Ehn NL, Cooper ME, Orr K, Shi M, Johnson MK, Caprau D, Dagle J, Steffen K, Johnson K, Marazita ML, et al. 2007. Evaluation of fetal and maternal genetic variation in the progesterone receptor gene for contributions to preterm birth. Pediatr Res 62: 630-635.

Emera D, Wagner GP. 2012. Transformation of a transposon into a derived prolactin promoter with function during human pregnancy. Proc Natl Acad Sci 109: 11246-11251. 
Emera D, Casola C, Lynch VJ, Wildman DE, Agnew D, Wagner GP. 2012. Convergent evolution of endometrial prolactin expression in primates, mice, and elephants through the independent recruitment of transposable elements. Mol Biol Evol 29: 239-247.

Fadem BH, Rayve RS. 1985. Characteristics of the oestrous cycle and influence of social factors in grey short-tailed opossums (Monodelphis domestica). J Reprod Fertil 73: 337-342.

Feschotte C. 2008. Transposable elements and the evolution of regulatory networks. Nat Rev Genet 9: 397-405.

Freyer C, Zeller U, Renfree MB. 2003. The marsupial placenta: A phylogenetic analysis. J Exp Zool A Comp Exp Biol 299: 59-77.

Gobbetti A, Zerani M, DiFiore MM, Botte V. 1993. PGF $_{2 \alpha}$ $\mathrm{PGE}_{2}$, progesterone, and estradiol-17 $\beta$, secretion by the corpus luteum of the oviparous lizard, Podarcis sicula sicula. In vitro studies. Prostaglandins 45: 159-166.

Golander A, Kopel R, Lazebnik N, Frenkel Y, Spirer Z. 1985. Decreased prolactin secretion by decidual tissue of preeclampsia in vitro. Acta Endocrinol (Copenh) 108: 111113.

Goldenberg RL, Culhane JF, Iams JD, Romero R. 2008. Epidemiology and causes of preterm birth. Lancet 371: $75-$ 84.

Guillette LJ Jr. 1990. Prostaglandins and reproduction in reptiles. Prog Clin Biol Res 342: 603-607.

Guillette LJ Jr, Dubois DH, Cree A. 1991. Prostaglandins, oviducal function, and parturient behavior in nonmammalian vertebrates. Am J Physiol 260: R854-R861.

Guoyang L, Morgan T, Bahtiyar MO, Snegovskikh VV, Schatz F, Kuczynski E, Funai EF, Dulay AT, Huang ST, Buhimschi CS, et al. 2008. Single nucleotide polymorphisms in the human progesterone receptor gene and spontaneous preterm birth. Reprod Sci 15: 147-155.

Haataja R, Karjalainen MK, Luukkonen A, Teramo K, Puttonen $\mathrm{H}$, Ojaniemi M, Varilo T, Chaudhari BP, Plunkett J, Murray JC, et al. 2011. Mapping a new spontaneous preterm birth susceptibility gene, IGF1R, using linkage, haplotype sharing, and association analysis. PLoS Genet 7: e1001293.

Haig D. 1993. Genetic conflicts in human pregnancy. Q Rev Biol 68: 495-532.

Hamilton BE, Martin JA, Ventura SJ. 2013. Births: Preliminary data for 2012. Natl Vital Stat Rep 62: 1-20.

Hammond KA, Diamond J. 1997. Maximal sustained energy budgets in humans and animals. Nature 386: 457462.

Harms MJ, Eick GN, Goswami D, Colucci JK, Griffin PR, Ortlund EA, Thornton JW. 2013. Biophysical mechanisms for large-effect mutations in the evolution of steroid hormone receptors. Proc Natl Acad Sci 110: 1147511480.

Hautier L, Stansfield FJ, Allen WR, Asher RJ. 2012. Skeletal development in the African elephant and ossification timing in placental mammals. Proc Biol Sci 279: 2188 2195.

Irwin RW, Yao J, Hamilton RT, Cadenas E, Brinton RD, Nilsen J. 2008. Progesterone and estrogen regulate oxidative metabolism in brain mitochondria. Endocrinology 149: $3167-3175$
Karjalainen MK, Huusko JM, Ulvila J, Sotkasiira J, Luukkonen A, Teramo K, Plunkett J, Anttila V, Palotie A, Haataja $\mathrm{R}$, et al. 2012. A potential novel spontaneous preterm birth gene, $A R$, identified by linkage and association analysis of $\mathrm{X}$ chromosomal markers. PLOS ONE 7: e51378.

Kastner P, Krust A, Turcotte B, Stropp U, Tora L, Gronemeyer H, Chambon P. 1990. Two distinct estrogen-regulated promoters generate transcripts encoding the two functionally different human progesterone receptor forms A and B. EMBO J 9: 1603-1614.

Kistka ZA, DeFranco EA, Ligthart L, Willemsen G, Plunkett J, Muglia LJ, Boomsma DI. 2008. Heritability of parturition timing: An extended twin design analysis. $\mathrm{Am} \mathrm{JOb-}$ stet Gynecol 199: 43.e1-43.e5.

Kurz C, Tempfer CB, Boecskoer S, Unfried G, Nagele F, Hefler LA. 2001. The PROGINS progesterone receptor gene polymorphism and idiopathic recurrent miscarriage. J Soc Gynecol Investig 8: 295-298.

Labhsetwar AP, Enders AC. 1968. Progesterone in the corpus luteum and placenta of the armadillo, Dasypus novemcinctus. J Reprod Fertil 16: 381-387.

Lalioti MD. 2011. Impact of follicle stimulating hormone receptor variants in fertility. Curr Opin Obstet Gynecol 23: $158-167$.

Liggins GC, Fairclough RJ, Grieves SA, Kendall JZ, Knox BS. 1973. The mechanism of initiation of parturition in the ewe. Recent Prog Horm Res 29: 111-159.

Lueders I, Niemuller C, Rich P, Gray C, Hermes R, Goeritz F, Hildebrandt TB. 2012. Gestating for 22 months: Luteal development and pregnancy maintenance in elephants. Proc Biol Sci 279: 3687-3696.

Lynch VJ, Leclerc RD, May G, Wagner GP. 2011. Transposon-mediated rewiring of gene regulatory networks contributed to the evolution of pregnancy in mammals. Nat Genet 43: 1154-1159.

Mahendroo MS, Porter A, Russell DW, Word RA. 1999. The parturition defect in steroid $5 \alpha$-reductase type 1 knockout mice is due to impaired cervical ripening. Mol Endocrinol 13: 981-992.

Manuck TA, Major HD, Varner MW, Chettier R, Nelson L, Esplin MS. 2010a. Progesterone receptor genotype, family history, and spontaneous preterm birth. Obstet Gynecol 115: 765-770.

Manuck TA, Price TM, Thom E, Meis PJ, Dombrowski MP, Sibai B, Spong CY, Rouse DJ, Iams JD, Simhan HN, et al. 2010b. Absence of mitochondrial progesterone receptor polymorphisms in women with spontaneous preterm birth. Reprod Sci 17: 913-916.

Manuck TA, Lai Y, Meis PJ, Dombrowski MP, Sibai B, Spong CY, Rouse DJ, Durnwald CP, Caritis SN, Wapner RJ, et al. 2011. Progesterone receptor polymorphisms and clinical response to 17- $\alpha$-hydroxyprogesterone caproate. Am J Obstet Gynecol 205: 135 e131-e139.

March of Dimes, PMNCH, Save the Children. 2012. Born too soon: The global action report on preterm birth. In Save the children (ed. Howson CP, Lawn JE). PMNCH, Geneva, Switzerland.

McElroy JJ, Gutman CE, Shaffer CM, Busch TD, Puttonen H, Teramo K, Murray JC, Hallman M, Muglia LJ. 2013. Maternal coding variants in complement receptor 1 and 
K.A. Swaggart et al.

spontaneous idiopathic preterm birth. Hum Genet 132: 935-942.

Mendelson CR. 2009. Minireview: Fetal-maternal hormonal signaling in pregnancy and labor. Mol Endocrinol 23: 947-954.

Merlino AA, Welsh TN, Tan H, Yi LJ, Cannon V, Mercer BM, Mesiano S. 2007. Nuclear progesterone receptors in the human pregnancy myometrium: Evidence that parturition involves functional progesterone withdrawal mediated by increased expression of progesterone receptor-A. J Clin Endocrinol Metab 92: 1927-1933.

Mesiano S. 2004. Myometrial progesterone responsiveness and the control of human parturition. J Soc Gynecol Investig 11: 193-202.

Mesiano S, Chan EC, Fitter JT, Kwek K, Yeo G, Smith R. 2002. Progesterone withdrawal and estrogen activation in human parturition are coordinated by progesterone receptor A expression in the myometrium. J Clin Endocrinol Metab 87: 2924-2930.

Mitchell BF, Taggart MJ. 2009. Are animal models relevant to key aspects of human parturition? Am J Physiol Regul Integr Comp Physiol 297: R525-R545.

Muglia LJ, Katz M. 2010. The enigma of spontaneous preterm birth. N Engl J Med 362: 529-535.

Nakakura K, Czekala NM, Lasley BL, Benirschke K. 1982. Fetal-maternal gradients of steroid hormones in the ninebanded armadillo (Dasypus novemcinctus). J Reprod Fertil 66: 635-643.

Neilson JP. 2000. Mifepristone for induction of labour. Cochrane Database Syst Rev 4: CD002865.

Nnamani MC, Plaza S, Romero R, Wagner GP. 2013. Evidence for independent evolution of functional progesterone withdrawal in primates and guinea pigs. Evol Med Public Health 2013: 273-288.

Pickrell JK, Coop G, Novembre J, Kudaravalli S, Li JZ, Absher D, Srinivasan BS, Barsh GS, Myers RM, Feldman MW, et al. 2009. Signals of recent positive selection in a worldwide sample of human populations. Genome Res 19: $826-837$.

Plunkett J, Muglia LJ. 2008. Genetic contributions to preterm birth: Implications from epidemiological and genetic association studies. Ann Med 40: 167-195.

Plunkett J, Feitosa MF, Trusgnich M, Wangler MF, Palomar L, Kistka ZA, DeFranco EA, Shen TT, Stormo AE, Puttonen $\mathrm{H}$, et al. 2009. Mother's genome or maternally-inherited genes acting in the fetus influence gestational age in familial preterm birth. Hum Hered 68: 209-219.

Plunkett J, Doniger S, Morgan T, Haataja R, Hallman M, Puttonen H, Menon R, Kuczynski E, Norwitz E, Snegovskikh V, et al. 2010. Primate-specific evolution of noncoding element insertion into PLA2G4C and human preterm birth. BMC Med Genomics 3: 62.

Plunkett J, Doniger S, Orabona G, Morgan T, Haataja R, Hallman M, Puttonen H, Menon R, Kuczynski E, Norwitz E, et al. 2011. An evolutionary genomic approach to identify genes involved in human birth timing. PLoS Genet 7: e1001365.

Ratajczak CK, Fay JC, Muglia LJ. 2010. Preventing preterm birth: The past limitations and new potential of animal models. Dis Model Mech 3: 407-414.
Renfree MB, Shaw G, Fletcher TP. 1994. Evidence for the essential role of prostaglandins for parturition in a marsupial, Macropus engenii. J Reprod Fertil 102: 433-446.

Roizen JD, Asada M, Tong M, Tai HH, Muglia LJ. 2008. Preterm birth without progesterone withdrawal in 15hydroxyprostaglandin dehydrogenase hypomorphic mice. Mol Endocrinol 22: 105-112.

Romano A, Delvoux B, Fischer DC, Groothuis P. 2007. The PROGINS polymorphism of the human progesterone receptor diminishes the response to progesterone. J Mol Endocrinol 38: 331-350.

Rosenberg K, Trevathan W. 2002. Birth, obstetrics and human evolution. BJOG 109: 1199-1206.

Rowe SM, Coughlan SJ, McKenna NJ, Garrett E, Kieback DG, Carney DN, Headon DR. 1995. Ovarian carcinoma-associated TaqI restriction fragment length polymorphism in intron $\mathrm{G}$ of the progesterone receptor gene is due to an Alu sequence insertion. Cancer Res 55: $2743-$ 2745.

Sartorius CA, Melville MY, Hovland AR, Tung L, Takimoto GS, Horwitz KB. 1994. A third transactivation function (AF3) of human progesterone receptors located in the unique $\mathrm{N}$-terminal segment of the B-isoform. Mol Endocrinol 8: $1347-1360$.

Sosenko IR, Frank L. 1987. Lung development in the fetal guinea pig: Surfactant, morphology, and premature viability. Pediatr Res 21: 427-431.

Stansfield FJ, Allen WR. 2012. Luteal maintenance of pregnancy in the African elephant (Loxodonta africana). Reproduction 143: 845-854.

Stempfle G, McGowen MR, Caravas JA, Wildman DE. 2013. From PPROM to caul: The evolution of membrane rupture in mammals. Appl Transl Genomics 2: 70-77.

Stout EP, La Clair JJ, Snell TW, Shearer TL, Kubanek J. 2010. Conservation of progesterone hormone function in invertebrate reproduction. Proc Natl Acad Sci 107: 1185911864.

Thornton JW. 2001. Evolution of vertebrate steroid receptors from an ancestral estrogen receptor by ligand exploitation and serial genome expansions. Proc Natl Acad Sci 98: 5671-5676.

Thornton JW, Need E, Crews D. 2003. Resurrecting the ancestral steroid receptor: Ancient origin of estrogen signaling. Science 301: 1714-1717.

Trilla CC, Medina MC, Ginovart G, Betancourt J, Armengol JA, Calaf J. 2014. Maternal risk factors and obstetric complications in late preterm prematurity. Eur J Obstet Gynecol Reprod Biol 179: 105-109.

Trotter A, Ebsen M, Kiossis E, Meggle S, Kueppers E, Beyer C, Pohlandt F, Maier L, Thome UH. 2006. Prenatal estrogen and progesterone deprivation impairs alveolar formation and fluid clearance in newborn piglets. Pediatr Res 60: 60-64.

Trotter A, Kipp M, Schrader RM, Beyer C. 2009. Combined application of $17 \beta$-estradiol and progesterone enhance vascular endothelial growth factor and surfactant protein expression in cultured embryonic lung cells of mice. Int $J$ Pediatr 2009: 170491.

Uzun A, Laliberte A, Parker J, Andrew C, Winterrowd E, Sharma S, Istrail S, Padbury JF. 2012a. dbPTB: A database for preterm birth. Database (Oxford) 2012: bar069. 
Uzun A, Sharma S, Padbury J. 2012b. A bioinformatics approach to preterm birth. Am J Reprod Immunol 67: 273277.

Uzun A, Dewan AT, Istrail S, Padbury JF. 2013. Pathwaybased genetic analysis of preterm birth. Genomics 101: $163-170$.

Vegeto E, Shahbaz MM, Wen DX, Goldman ME, O’Malley BW, McDonnell DP. 1993. Human progesterone receptor A form is a cell- and promoter-specific repressor of human progesterone receptor B function. Mol Endocrinol 7: 1244-1255.

Voight BF, Kudaravalli S, Wen X, Pritchard JK. 2006. A map of recent positive selection in the human genome. PLoS Biol 4: e72.

Wagner CK. 2008. Progesterone receptors and neural development: A gap between bench and bedside? Endocrinology 149: 2743-2749.

Wagner GP, Tong Y, Emera D, Romero R. 2012. An evolutionary test of the isoform switching hypothesis of functional progesterone withdrawal for parturition: Humans have a weaker repressive effect of PR-A than mice. J Perinat Med 40: 345-351.
Wagner G, Kin K, Muglia L, Pavlicev M. 2014. Evolution of mammalian pregnancy and the origin of the decidual stromal cell. Int J Dev Biol 58: 117-126.

Weiner S, Monge J, Mann A. 2008. Bipedalism and parturition: An evolutionary imperative for cesarean delivery? Clin Perinatol 35: 469-478, ix.

Wittman AB, Wall LL. 2007. The evolutionary origins of obstructed labor: Bipedalism, encephalization, and the human obstetric dilemma. Obstet Gynecol Surv 62: 739-748.

Word RA, Landrum CP, Timmons BC, Young SG, Mahendroo MS. 2005. Transgene insertion on mouse chromosome 6 impairs function of the uterine cervix and causes failure of parturition. Biol Reprod 73: 1046-1056.

Yawno T, Mortale M, Sutherland AE, Jenkin G, Wallace EM, Walker DW, Miller SL. 2014. The effects of betamethasone on allopregnanolone concentrations and brain development in preterm fetal sheep. Neuropharmacology 85: 342-348.

Zeng Z, Velarde MC, Simmen FA, Simmen RC. 2008. Delayed parturition and altered myometrial progesterone receptor isoform A expression in mice null for Krüppel-like factor 9. Biol Reprod 78: 1029-1037. 


\section{$\&_{\mathrm{CSH}}^{\infty} \&$ Cold Spring Harbor \\ $\stackrel{\text { Perspectives }}{\longrightarrow \infty_{\infty}}$ Perspectives in Medicine}

\section{Genomics of Preterm Birth}

Kayleigh A. Swaggart, Mihaela Pavlicev and Louis J. Muglia

Cold Spring Harb Perspect Med 2015; doi: 10.1101/cshperspect.a023127

Subject Collection Molecular Approaches to Reproductive and Newborn Medicine

Intergenerational Transfer of Epigenetic

Information in Sperm

Oliver J. Rando

\section{Effects of Maternal Obesity on Fetal Programming: Molecular Approaches Caterina Neri and Andrea G. Edlow}

The Neonatal Salivary Transcriptome Jill L. Maron

The Role of Hox Genes in Female Reproductive Tract Development, Adult Function, and Fertility Hongling Du and Hugh S. Taylor

\author{
Molecular Cross-Talk at the Feto-Maternal \\ Interface \\ Gendie E. Lash
}

Molecular Regulation of Parturition: A Myometrial Perspective

Nora E. Renthal, Koriand'r C. Williams, Alina P. Montalbano, et al.

Genome-Wide Sequencing for Prenatal Detection of Fetal Single-Gene Disorders

Ignatia B. Van den Veyver and Christine M. Eng

MicroRNA in Ovarian Biology and Disease

Lynda K. McGinnis, Lacey J. Luense and Lane K. Christenson
A Molecular Perspective on Procedures and Outcomes with Assisted Reproductive Technologies Monica A. Mainigi, Carmen Sapienza, Samantha Butts, et al.

Whole-Exome Sequencing and Whole-Genome Sequencing in Critically III Neonates Suspected to Have Single-Gene Disorders Laurie D. Smith, Laurel K. Willig and Stephen F. Kingsmore

Noninvasive Antenatal Determination of Fetal

Blood Group Using Next-Generation Sequencing Klaus Rieneck, Frederik Banch Clausen and Morten Hanefeld Dziegiel

Potential Uses and Inherent Challenges of Using Genome-Scale Sequencing to Augment Current Newborn Screening Jonathan S. Berg and Cynthia M. Powell

Molecular Regulation of Parturition: The Role of the Decidual Clock Errol R. Norwitz, Elizabeth A. Bonney, Victoria V. Snegovskikh, et al.

Molecular Mechanisms of Preeclampsia Tammy Hod, Ana Sofia Cerdeira and S. Ananth Karumanchi

Noninvasive Prenatal Screening for Genetic Diseases Using Massively Parallel Sequencing of Maternal Plasma DNA Lyn S. Chitty and Y. M. Dennis Lo

Confrontation, Consolidation, and Recognition: The Oocyte's Perspective on the Incoming Sperm David Miller

For additional articles in this collection, see http://perspectivesinmedicine.cshlp.org/cgi/collection/ 